\title{
Stimulatory Effect of Whole Coffee Fruit Concentrate Powder on Plasma Levels of Total and Exosomal Brain-Derived Neurotrophic Factor in Healthy Subjects: An Acute Within-Subject Clinical Study
}

\author{
Tania Reyes-Izquierdo ${ }^{1 *}$, Ruby Argumedo ${ }^{1}$, Cynthia Shu ${ }^{1}$, Boris Nemzer ${ }^{2}$, Zb Pietrzkowski ${ }^{1}$
}

${ }^{1}$ Applied BioClinical Inc., Irvine, USA; ${ }^{2}$ FutureCeuticals Inc., Momence, USA.

Email: ${ }^{*}$ Tania@abclinicaldiscovery.com

Received June $2^{\text {nd }}, 2013$; revised July $2^{\text {nd }}, 2013$; accepted July $9^{\text {th }}, 2013$

Copyright (C) 2013 Tania Reyes-Izquierdo et al. This is an open access article distributed under the Creative Commons Attribution License, which permits unrestricted use, distribution, and reproduction in any medium, provided the original work is properly cited.

\begin{abstract}
A pilot study by Reyes [1] previously showed that ingestion of single dose of whole coffee fruit concentrate (WCFC) powder increased blood levels of brain derived neurotrophic factor (BDNF) during the first 60 minutes after ingestion. In the present report, we performed a single dose, placebo-controlled, within-subject study to confirm and further investigate this effect. Twenty healthy subjects with ages ranging from 25 to 35 participated in this study. All fasted and resting subjects received placebo on Day 1, WCFC on Day 2, and a cup of freshly brewed coffee on Day 3. Treatment with WCFC resulted in a statistically significant increase in plasma BDNF compared to placebo $(p=0.0073)$ or coffee $(\mathrm{p}=0.0219)$ during first 60 minutes. In addition, e isolated exosomes from serum and found that they contained BDNF. Furthermore, oral WCFC consumption acutely increased BDNF levels in serum exosomes. In summary, all presented results justify further clinical investigation of WCFC as a tool to manage BDNF-dependent health conditions.
\end{abstract}

Keywords: Brain-Derived Neurotrophic Factor; Whole Coffee Fruit Concentrate; Coffee; Exosomes; Acute Effect

\section{Introduction}

Brain-derived neurotrophic factor (BDNF) is a member of the neurotrophin family of growth factors, along with nerve growth factor, neurotrophin N4/5, and neurotrophin NT6. BDNF has high affinity for the tropomyosin-related kinase B (TrkB) receptor [2,3]. This product of the NTRK gene is expressed in several types of cells and tissues with major expression in neural cells and cardiomyocytes [4]. BDNF exerts several effects in the central nervous system: it regulates the development and differentiation of new neurons [5-7] and promotes neuron survival [8-10]; it influences mood and depression [1113]; it controls sleep [14] and modulates appetite $[15,16]$. In addition, alterations in BDNF have been identified in various chronic neurodegenerative diseases [17]. Blood BDNF declines during aging [18] and decreased levels may be associated with depression [19]. Preclinical studies demonstrate that both BDNF and TrkB receptor ago-

*Corresponding author. nists have antidepressant effects in an animal model of depression [20-23]. In humans suffering from depression, blood levels of BDNF are lower than in healthy controls [24].

BDNF may act through TrkB receptors not only in brain cells, but also in several peripheral tissues. Blood circulating BDNF and BDNF found in peripheral organs and tissues may interact with the TrkB receptor to modulate glucose metabolism [25-27], energy expenditure [25,27], total food intake [25], and stimulation of Glut 4 expression in muscle tissue [28]. Both central and peripheral administration of BDNF lowers blood glucose and increases energy expenditure in diabetic animals [29]. Conversely, haploinsufficiency of the BDNF gene results in hyperphagy and obesity [30,31].

Several types of cells within the human body express BDNF mRNA [32] and the corresponding BDNF peptides are stored for rapid release. BDNF can be rapidly released from various types of blood cells including platelets [33-35] peripheral blood mononuclear cells [36], 
eosinophils [37-39], monocytes [40]. Interestingly, all of these cells can release exosomes [41,42]. Exosomes are $40-50 \mathrm{~nm}$ vesicles found in various cell types (for review, see Simons and Raposo [43]. Blood-circulating exosomes carry mRNA, microRNA, and proteins characteristic of the cells that release the exosomes.

Circulating exosomes can fuse with other cells and transmit internal macromolecules, such as microRNA or peptides $[43,44]$. Therefore, exosomes may function as a communication vehicle between different cells and tissues [45]. Recently, researchers were able to detect exosomes in blood that had been released from brain cells $[46,47]$ indicating that exosomes can cross the brain-blood barrier (BBB) [46,47]. Likewise, exosomes released into blood may pass the BBB and deliver their exosomal content [48]. Such an arrangement would suggest that exosomes are of potential therapeutic value as a means to deliver substances to brain that do not normally cross the BBB [49].

We previously reported that WCFC acutely increases blood levels of BDNF in a small number of healthy subjects [1]. This preliminary study was limited by the small number of participants and by the fact that the chosen placebo, silica oxide, unexpectedly reduced BDNF levels in blood. We now report the results of a larger clinical trial that further clarifies the effect of WCFC on BDNF. We also provide evidence that blood exosomes contain BDNF and that treatment with WCFC may increase exosomal BDNF content.

\section{Materials and Methods}

\subsection{Materials}

WCFC is a patented extract of whole coffee fruit (coffee cherries) from Coffeaarabica. WCFC tested in this study was provided by Future Ceuticals, Inc., Momence, IL, USA. Chemical composition and polyphenol profile of this material was previously reported [1]. Dulbecco's phosphate buffered saline (PBS) and water were purchased from Sigma Chem. Co. (St. Louis, MO, USA). Protein Low Binding microtubes were obtained from Eppendorf (Hauppauge, NY, USA) and RC DC Protein Assay Kit II was from Bio-Rad (Palo Alto, CA, USA). Human BDNF Quantikine ELISA kits were from R\&D Systems (Minneapolis, MN USA). Heparin blood collection tubes were obtained from Ram Scientific Inc. (Yonkers, NY) and lancets were purchased from Medlance ${ }^{\circledR}$ (Ozorkow, Poland). Placebo was empty gelatin capsules obtained from Capsuline, Inc. (Pompano Beach, FL, USA). Coffee was prepared in a Platinum B70 Keurig $^{\circledR}$ brewer (Keurig Incorporated, Reading MA, USA) and brewed to $150 \mathrm{~mL}$ cup size. Afterwards, 150 $\mathrm{mL}$ cold water was added per cup to cool down the coffee for fast consumption. The pre-packed selected coffee was San Francisco Bay Coffee One Cup for Keurig K-Cup Brewers, French Roast (San Francisco, CA, USA) which contains $130 \pm 10 \mathrm{mg}$ of caffeine.

This study was conducted according to the guidelines put forth in the Declaration of Helsinki and all procedures involving human subjects were approved by the Institutional Review Board at Vita Clinical S.A. AvenidaCircunvalacion Norte \#135, Guadalajara, JAL, Mexico 44,270 (Study protocol ABC-WCFC). All study subjects were generally healthy and did not use any type of medication or supplement for a period of 15 days prior to the start of the study. The inclusion criteria required participants to be between the ages of 25 and 35 and have a body mass index between 18.5 and $24.9 \mathrm{~kg} / \mathrm{m}^{2}$ [50]. At the time of the study, participants were free of rhinitis, influenza, and any other symptoms of upper respiratory infection. Participants were excluded if they had diabetes mellitus, a known allergy to any of the test ingredients or were using any anti-inflammatory, analgesic, anti-allergy, anti-depressant medication or multivitamins. Participants received oral and written information about the experimental procedures and written consent was obtained before administration of any study treatment.

\subsection{Study Description}

Twenty (20) subjects meeting inclusion criteria were treated with placebo on Day 1, a single dose of WCFC on Day 2, and $300 \mathrm{~mL}$ of freshly brewed coffee on the Day 3. In all cases, subjects fasted for $12 \mathrm{~h}$ prior to the first blood collection. Other than consuming one of the given materials, patients had no intake per os during the study period and remained calm and resting. One hundred $\mu \mathrm{L}$ of finger blood were collected by finger puncture and placed in Safe-T-Fill ${ }^{\circledR}$ Lithium heparin capillary blood collection tubes (Ram Scientific Inc. Yonkers, NY) at baseline (T0). Subsequent samples were collected every $60 \mathrm{~min}$ (T60 and T120) after treatment.

\subsection{BDNF Detection and Quantification}

Heparin plasma was isolated from collected blood samples using centrifugation at $1000 \times \mathrm{g}$ for $10 \mathrm{~min}$. Human mature BDNF (aa129-247) was detected using a quantitative sandwich ELISA immunoassay (R\&D Systems; Minneapolis, MN, USA) following the instructions provided. Final reactions were measured using a Molecular Devices spectrophotometer (Sunnyvale, CA, USA) and BDNF concentrations were determined based on a standard curve as described in the instruction.

\subsection{Determination of Exosomal BDNF (Clinical Case Experimentation)}

For exosome isolation, $500 \mu \mathrm{L}$ of blood were collected 
from finger puncture in serum collections tubes. Blood was spun down at $1000 \mathrm{~g}$ for $10 \mathrm{~min}$. Two-hundred fifty $\mu \mathrm{L}$ of serum were used for exosome separation by precipitation using ExoQuick ${ }^{\mathrm{TM}}$ Exosome Precipitation Kit (System Biosciences, Mountain View CA, USA) following the instructions from the manufacturer. Briefly, 63 $\mu \mathrm{L}$ of exosome precipitation solution were added to 250 $\mu \mathrm{L}$ of serum. The samples were gently mixed to ensure uniformity and then incubated at $4^{\circ} \mathrm{C}$ for $30 \mathrm{~min}$. Afterwards, samples were centrifuged at room temperature for $30 \mathrm{~min}$ at $1500 \mathrm{~g}$. The supernatant was collected in a clean tube while the pellet was spun again for $5 \mathrm{~min}$ at $1500 \mathrm{~g}$ and any remaining supernatant was removed. Finally, the pellet was resuspended in $250 \mu \mathrm{L}$ of Exosome Binding buffer (System Biosciences, Mountain View, CA, USA) and incubated in an ice bath for $5 \mathrm{~min}$ to complete the lytic process. BDNF contained in the exosomal lysate was measured using the quantitative sandwich ELISA immunoassay (R\&D Systems; Minneapolis, MN, USA) previously described.

\subsection{Lactate and Glucose Measurements}

Blood lactate was measured using an Accutrend ${ }^{\mathbb{B}}$ Lactate Point of Care (Roche, Mannheim, Germany) and BMLactate Strips ${ }^{\circledR}$ (Roche, Mannheim, Germany). Twelve $\mu \mathrm{L}$ of blood were loaded onto the strip and lactate was read according to the instructions provided by the manufacturer. Glucose was measured using an Accu-Chek ${ }^{\circledR}$ Compact Plus glucometer (Roche Diagnostics, Indianapolis, IN, USA) and Accu-Chek ${ }^{\circledR}$ test strips (Roche Diagnostics, Indianapolis, IN, USA). After blood was collected for BDNF assays, fingers were wiped off and a glucose test was performed on fresh blood. Glucose was read according to the instructions provided by the manufacturer.

\subsection{Statistical Analysis}

As previously described [1], BDNF levels were compared to a reference standard curve and each subject was normalized to their own value measured at time zero (T0). Results from each group were pooled and standard error of the mean was used for each separate analysis. Plasma BDNF levels for 60 and 120 minutes after treatment were compared within experimental groups to baseline and between experimental groups using a one-way ANOVA with Tukey's post hoc analysis. Descriptive analyses were run in $\mathrm{GraphPad}^{\mathbb{B}}$ to derive mean and standard deviation for each group.

\section{Results}

Twenty healthy volunteers were recruited for this withinsubject crossover clinical study. On Day 1, participants consumed an empty capsule labeled as placebo. On Day 2, $100 \mathrm{mg}$ of WCFC was administered orally and on Day 3 , they consumed fresh-brewed coffee. On each day, blood samples were drawn at baseline and at 60 and 120 minutes after treatment. As shown in Figure 1, a single $100 \mathrm{mg}$ dose of capsulated WCFC increased plasma BDNF by $91 \%$ at 60 minutes and $66 \%$ at 120 minutes compared to baseline $(\mathrm{p}<0.001)$. Placebo increased plasma BDNF by $5 \%(\mathrm{p}=0.5)$ at $\mathrm{T} 60$ and $26 \%(\mathrm{p}=0.02)$ at T120 over baseline. Treatment with fresh coffee resulted in $21 \%$ and $15 \%$ change at $\mathrm{T} 60(\mathrm{p}=0.1)$ and $\mathrm{T} 120$ $(\mathrm{p}=0.2)$ over baseline, respectively (Figure 1). At 60 minutes, plasma BDNF in subjects treated with WCFC was higher than those treated with placebo $(p=0.0073)$. This difference diminished at $120 \mathrm{~min}(\mathrm{p}=0.1127)$. WCFC treatment also increased BDNF levels significantly more than fresh coffee consumption at $60 \mathrm{~min}(\mathrm{p}=$ $0.02)$ and $120 \mathrm{~min}(\mathrm{p}=0.04)$. The coffee treatment did not significantly alter BDNF levels when compared to placebo at $60 \mathrm{~min}(\mathrm{p}=0.23)$ or $120 \mathrm{~min}(\mathrm{p}=0.138)$. Blood levels of glucose (Figure 2A) and lactate (Figure 2B) were not changed by any of the three treatments (placebo, WCFC, coffee) compared to baseline.

We were interested in determining whether treatment with WCFC increases only free BDNF levels in the blood or whether exosomal BDNF levels change as well. After the within-subject crossover study, we selected one participant at random to receive an additional dose of WCFC. We collected serum samples at T0, T60 and T120 as before. The exosome fraction was isolated using standard procedures provided with the exosome isolation kit. BDNF levels in the exosome fraction and remaining serum from one volunteer are presented in Figure 3.

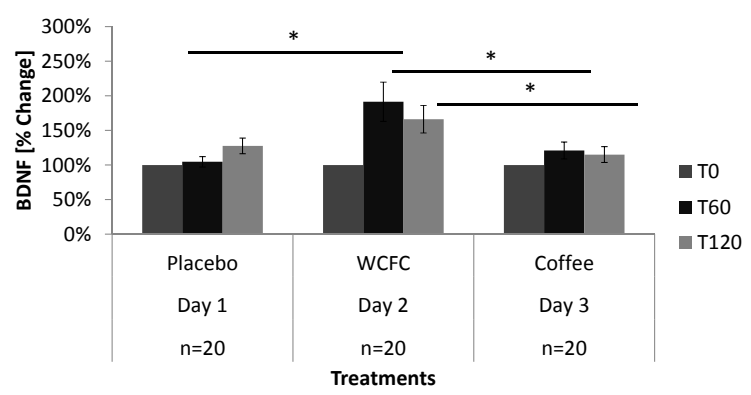

Figure 1. The effect of WCFC on BDNF. Plasma BDNF levels were measured at baseline (T0), 60 (T60) and 120 (T120) min after treatment. Subjects were treated with Placebo (Day 1), $100 \mathrm{mg}$ WCFC (Day 2) and $300 \mathrm{~mL}$ of diluted coffee (Day 3). Data are presented as the average percentage difference compared to baseline. "Mean value of WCFC treatment was significantly different when compared with placebo $(p=0.007)$ and coffee $(p=0.02)$ at T60. Results were not significant at $\mathrm{T120}$ when compared to the placebo $(p=0.11)$, however, they are significant when compared to coffee $(p=0.04)$. 

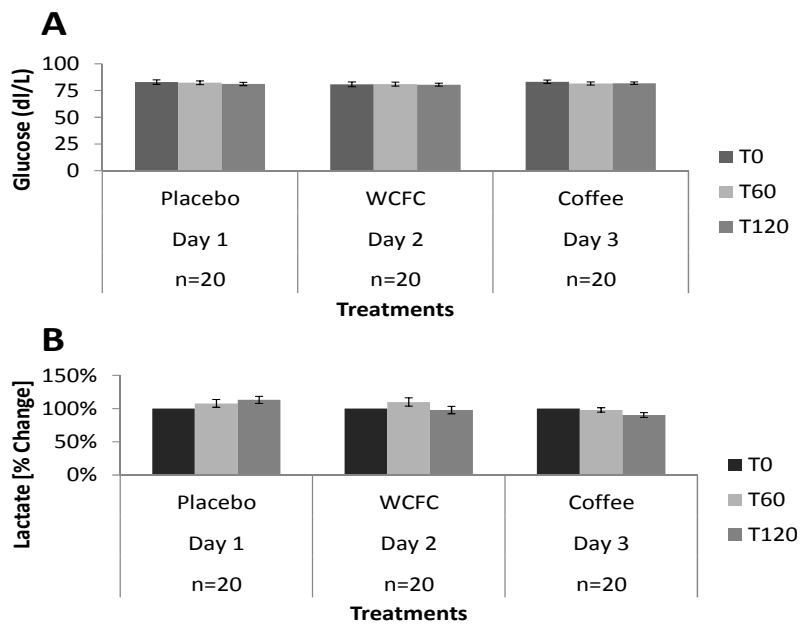

Figure 2. Blood glucose levels (A) and lactate levels (B) remained unchanged at baseline, 60 and 120 min after treatment with placebo (Day 1), WCFC (Day 2) and coffee (Day 3). No significant differences were observed between treatments or over time.

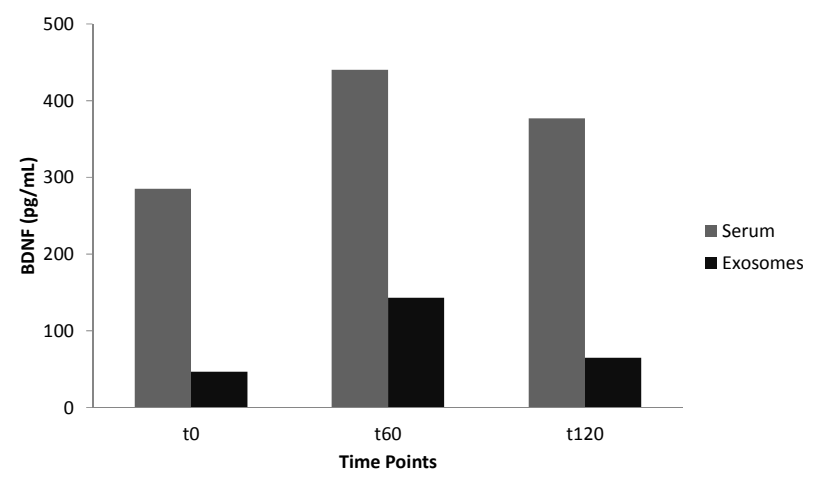

Figure 3. Exosomal BDNF after treatment with WCFC. Exosomes were isolated from serum of one volunteer at baseline and at 60 and 120 minutes after treatment with WCFC. Preliminary results suggest that exosomal BDNF is increased after treatment.

BDNF was present in exosomes before treatment at T0. After 60 minutes, one dose of WCFC increased serum BDNF by $54 \%$ and exosomal BDNF by $206 \%$. The initial WCFC-induced increase in serum BDNF declined at 120 minutes (32\% over baseline) as did exosomal BDNF (39\% over baseline). This clinical case result suggests that acute treatment with WCFC may increase the amount of exosomal BDNF in blood; however this requires further investigation since data presented here are from a single study participant.

\section{Discussion}

We report that a single dose of WCFC nearly doubles the amount of BDNF in the blood after 60 minutes with sustained effects for at least two hours after treatment. This confirms and extends the results of our previous work [1]. This effect was not seen with freshly brewed coffee over the same time, a control that was not tested previously. This result is consistent, however, with our previous observation that coffee beans or green coffee extracts containing various amounts of caffeine do not raise BDNF levels in blood [1]. Since WCFC is an extract of whole coffee fruit, it does not contain BDNF. Thus, WCFC could be considered to be a stimulator of endogenous BDNF release from cells. As previously described, there are several types of mammalian cells capable of releasing BDNF. However, it remains to be determined which cells are stimulated by WCFC and by what mechanism.

In a previous study, we reported that the use of silica oxide as a placebo, slightly decreased levels of blood BDNF [1]. In the current study, empty gelatin capsules were used as placebo, showing a slight, but not significant increase in plasma BDNF (5\%) at T60, whilst BDNF blood levels increased up to $28 \%$ at T120. Coffee had no significant effect on BDNF at T60 and T120. While fasting is known to increase BDNF levels in brain $[51,52]$, this effect for serum in healthy individuals has not been clearly shown. In addition, studies of long term fasting on serum BDNF levels have yielded conflicting results $[53,54]$.

Since study participants fasted 12 hours prior to the start of the study, we monitored blood glucose for hypoglycemia. We also wanted to learn if WCFC affects blood levels of glucose or lactate. We confirmed our previous finding that WCFC does not affect glucose or lactate [1]. It is important to mention, that this study was conducted on healthy subjects. It is unclear what effect WCFC would have on subjects with chronic conditions, until additional trials have been conducted.

An acute increase in blood levels of BDNF may indicate that BDNF is released into bloodstream from cells [43]. Therefore, we hypothesized that at least part of the plasma BDNF detected was released from exosomes derived from blood cells. We report for the first time that blood-circulating BDNF may exist as both free BDNF and contained within exosomes. Free BDNF sharply increased one hour after WCFC treatment and began to return to baseline after two hours, as did exosomal BDNF. Further studies are needed to confirm that BDNF circulates in blood as both free BDNF and exosomal BDNF since this was the result obtained in a single subject (clinical case experiment). However, the initial result is encouraging. Since exosomes have the ability to cross the BBB [43], it would be interesting to study the effect of WCFC on BDNF-mediated brain functionalities such as cognitive activity [47], appetite control [55], or modulation of neurodegenerative conditions $[47,49,56,57]$. 


\section{Acknowledgements}

The present study was funded by Futureceuticals, Inc. T. R.-I. conducted the experimental work, analysed the data and led the manuscript writing. R. A. and C. S. performed serum tests and helped in the data analysis. B. N. designed and conducted all the chemical analysis. Z. P. designed and directed the study. We express our gratitude to John Hunter and Brad Evers (Future Ceuticals) for their comments and suggestions in the preparation of this article. We would like to thank Michael Sapko for his help in editing the manuscript. All authors declare that they have no conflicts of interest.

\section{REFERENCES}

[1] T. Reyes-Izquierdo, et al., "Modulatory Effect of Coffee Fruit Extract on Plasma Levels of Brain-Derived Neurotrophic Factor in Healthy Subjects," British Journal of Nutrition, Vol. 110, No. 3, 2013, pp. 420-425. doi:10.1017/S0007114512005338

[2] E. E. B. Noble, C. J. Kotz and C. M. Wang, "The Lighter Side of BDNF," American Journal of Physiology. Regulatory, Integrative and Comparative Physiology, Vol. 300, No. 5, 2011, pp. R1053-R1069. doi:10.1152/ajpregu.00776.2010

[3] R. N. Klein, J. Venkata, L. Shuqian, T. Fabienne, B. Peter, C.-C. Sherri, J. Carlos, R. Kevin, L. F. Reichardt and M. Barbacid, "The trkB Tyrosine Protein Kinase Is a Receptor for Brain-Derived Neurotrophic Factor and Neurotrophin-3," Cell, Vol. 66, No. 2, 1991, pp. 395-403.

[4] A. I. Su, T. Wiltshire, S. Batalov, H. Lapp, K. A. Ching, D. Block, J. Zhang, R. Soden, M. Hayakawa and G. Kreiman, "A Gene Atlas of the Mouse and Human Protein-Encoding Transcriptomes," Proceedings of the $\mathrm{Na}$ tional Academy of Sciences of the United States of America, Vol. 101, No. 16, 2004, pp. 6062-6067. doi:10.1073/pnas.0400782101

[5] R. F. A. Alderson, L. Andrea, Y.-A. Barde and R. M. Lindsay, "Brain-Derived Neurotrophic Factor Increases Survival and Differentiated Functions of Rat Septal Cholinergic Neurons in Culture," Neuron, Vol. 5, No. 3, 1990, pp. 297-306. doi:10.1016/0896-6273(90)90166-D

[6] B. Knüsel and F. Hefti, "K-252b Is a Selective and Nontoxic Inhibitor of Nerve Growth Factor Action on Cultured Brain Neurons," Journal of Neurochemistry, Vol. 57, No. 3, 1991, pp. 955-962. doi:10.1111/j.1471-4159.1991.tb08243.x

[7] R. F. Alderson, A. L. Alterman, Y.-A. Barde and R. M. Lindsay, "Brain-Derived Neurotrophic Factor Increases Survival and Differentiated Functions of Rat Septal Cholinergic Neurons in Culture," Neuron, Vol. 5, No. 3, 1990, pp. 297-306. doi:10.1111/j.1471-4159.1991.tb08243.x

[8] C. Grothe and K. Unsicker, "Neuron-Enriched Cultures of Adult Rat Dorsal Root Ganglia: Establishment, Characterization, Survival, and Neuropeptide Expression in Response to Trophic Factors," Journal of Neuroscience Re- search, Vol. 18, No. 4, 1987, pp. 539-550.

doi:10.1002/jnr.490180406

[9] M. Hofer and Y.-A. Barde, "Brain-Derived Neurotrophic Factor Prevents Neuronal Death in Vivo," Nature, Vol. 331, No. 6153, 1988, pp. 261-262.

[10] M. Sieber-Blum, "Role of the Neurotrophic Factors BDNF and NGF in the Commitment of Pluripotent Neural Crest Cells," Neuron, Vol. 6, No. 6, 1991, pp. 949-955. doi:10.1016/0896-6273(91)90235-R

[11] Y. Dwivedi, "Brain-Derived Neurotrophic Factor: Role in Depression and Suicide," Neuropsychiatric Disease and Treatment, Vol. 5, 2009, pp. 433-449. doi:10.2147/NDT.S5700

[12] A. R. Brunoni, M. Lopes and F. Fregni, "A Systematic Review and Meta-Analysis of Clinical Studies on Major Depression and BDNF Levels: Implications for the Role of Neuroplasticity in Depression," The International Journal of Neuropsychopharmacology, Vol. 11, No. 8, 2008, pp. 1169-1180. doi:10.1017/S1461145708009309

[13] G. Maina et al., "Serum Levels of Brain-Derived Neurotrophic Factor in Drug-Naive Obsessive-Compulsive Patients: A Case-Control Study," Journal of Affective Disorders, Vol. 122, No. 1-2, 2010, pp. 174-178. doi:10.1016/j.jad.2009.07.009

[14] I. A. Alhaider, A. M. Aleisa, T. T. Tran and K. A. Alkadhi, "Sleep Deprivation Prevents Stimulation-Induced Increases of Levels of P-CREB and BDNF: Protection by Caffeine," Molecular and Cellular Neurosciences, Vol. 46, No. 4, 2011, pp. 742-751. doi:10.1016/j.mcn.2011.02.006

[15] T. Yamamoto, A. Hirayama, N. Hosoe, M. Furube and S. Hirano, "Effects of Soft-Diet Feeding on BDNF Expression in Hippocampus of Mice," The Bulletin of Tokyo Dental College, Vol. 49, No. 4, 2008, pp. 185-190. doi:10.2209/tdcpublication.49.185

[16] T. Yamamoto, A. Hirayama, N. Hosoe, M. Furube and S. Hirano, "Soft-Diet Feeding Inhibits Adult Neurogenesis in Hippocampus of Mice," The Bulletin of Tokyo Dental College, Vol. 50, No. 3, 2009, pp. 117-124. doi:10.2209/tdcpublication.50.117

[17] C. Zuccato and E. Cattaneo, "Brain-Derived Neurotrophic Factor in Neurodegenerative Diseases," Nature Reviews. Neurology, Vol. 5, No. 6, 2009, pp. 311-322. doi:10.1038/nrneurol.2009.54

[18] Y. Muto, et al., "Age-Related Decrease in Brain-Derived Neurotrophic Factor Gene Expression in the Brain of the Zitter Rat with Genetic Spongiform Encephalopathy," Neuroscience Letters, Vol. 271, No. 2, 1999, pp. 69-72.

[19] K. Hashimoto, "Understanding Depression: Linking BrainDerived Neurotrophic Factor, Transglutaminase 2 and Serotonin," Expert Review of Neurotherapeutics, Vol. 13, No. 1, 2013, pp. 5-7. doi:10.1586/ern.12.140

[20] K. Hashimoto, "[Depression and BDNF]," Nihon Yakurigaku Zasshi. Folia Pharmacologica Japonica, Vol. 127, No. 3, 2006, pp. 201-204. doi:10.1254/fpj.127.201

[21] K. Hashimoto, "Brain-Derived Neurotrophic Factor as a Biomarker for Mood Disorders: An Historical Overview and Future Directions," Psychiatry and Clinical Neuro- 
sciences, Vol. 64, No. 4, 2010, pp. 341-357. doi:10.1111/j.1440-1819.2010.02113.x

[22] K. Hashimoto, "Sigma-1 Receptor Chaperone and BrainDerived Neurotrophic Factor: Emerging Links between Cardiovascular Disease and Depression," Progress in Neurobiology, Vol. 100, No. 1, 2013, pp. 15-29. doi:10.1016/j.pneurobio.2012.09.001

[23] K. Hashimoto, E. Shimizu and M. Iyo, "Critical Role of Brain-Derived Neurotrophic Factor in Mood Disorders," Brain Research. Brain Research Reviews, Vol. 45, No. 2, 2004, pp. 104-114. doi:10.1016/j.brainresrev.2004.02.003

[24] E. Shimizu, et al., "Alterations of Serum Levels of BrainDerived Neurotrophic Factor (BDNF) in Depressed Patients with or without Antidepressants," Biological Psychiatry, Vol. 54, No. 1, 2003, pp. 70-75. doi:10.1016/S0006-3223(03)00181-1

[25] M. Yamanaka, et al., "Intermittent Administration of Brain-Derived Neurotrophic Factor (BDNF) Ameliorates Glucose Metabolism and Prevents Pancreatic Exhaustion in Diabetic Mice," Journal of Bioscience and Bioengineering, Vol. 105, No. 4, 2008, pp. 395-402. doi:10.1263/jbb.105.395

[26] M. Yamanaka, et al., "Brain-Derived Neurotrophic Factor Enhances Glucose Utilization in Peripheral Tissues of Diabetic Mice," Diabetes, Obesity and Metabolism, Vol. 9, No. 1, 2007, pp. 59-64. doi:10.1111/j.1463-1326.2006.00572.x

[27] M. Yamanaka, Y. Itakura, A. Tsuchida, T. Nakagawa and M. Taiji, "Brain-Derived Neurotrophic Factor (BDNF) Prevents the Development of Diabetes in Prediabetic Mice," Biomedical Research, Vol. 29, No. 3, 2008, pp. 147-153. doi:10.2220/biomedres.29.147

[28] M. Suwa, et al., "Brain-Derived Neurotrophic Factor Treatment Increases the Skeletal Muscle Glucose Transporter 4 Protein Expression in Mice," Physiological Research/Academia Scientiarum Bohemoslovaca, Vol. 59, No. 4, 2010, pp. 619-623.

[29] T. Nakagawa, et al., "Brain-Derived Neurotrophic Factor Regulates Glucose Metabolism by Modulating Energy Balance in Diabetic Mice," Diabetes, Vol. 49, No. 3, 2000, pp. 436-444. doi:10.2337/diabetes.49.3.436

[30] J. Gray, et al., "Hyperphagia, Severe Obesity, Impaired Cognitive Function, and Hyperactivity Associated with Functional Loss of One Copy of the Brain-Derived Neurotrophic Factor (BDNF) Gene," Diabetes, Vol. 55, No. 12, 2006, pp. 3366-3371. doi:10.2337/db06-0550

[31] J. C. Han, et al., "Brain-Derived Neurotrophic Factor and Obesity in the WAGR Syndrome," New England Journal of Medicine, Vol. 359, No. 9, 2008, pp. 918-927.

[32] J. D. Abbott, H. N. Ahmed, H. A. Vlachos, F. Selzer and D. O. Williams, "Comparison of Outcome in Patients with ST-Elevation versus Non-ST-Elevation Acute Myocardial Infarction Treated with Percutaneous Coronary Intervention (from the National Heart, Lung, and Blood Institute Dynamic Registry)," The American Journal of Cardiology, Vol. 100, No. 2, 2007, pp. 190-195. doi:10.1016/j.amjcard.2007.02.083

[33] H. Fujimura, et al., "Brain-Derived Neurotrophic Factor
Is Stored in Human Platelets and Released by Agonist Stimulation," Thorombosis and Haemostasis, Vol. 87, No. 4, 2002, pp. 728-734.

[34] S. Tamura, et al., "Release Reaction of Brain-Derived Neurotrophic Factor (BDNF) through PAR1 Activation and Its Two Distinct Pools in Human Platelets," Thrombosis Research, Vol. 128, No. 5, 2011, pp. e55-e61. doi:10.1016/j.thromres.2011.06.002

[35] P. Stoll, A. Plessow, K. Bratke, J. C. Virchow and M. Lommatzsch, "Differential Effect of Clopidogrel and Aspirin on the Release of BDNF from Platelets," Journal of Neuroimmunology, Vol. 238, No. 1, 2011, pp. 104-106.

[36] P. Lalive, S. Kantengwa, M. Benkhoucha, C. Juillard and M. Chofflon, "Interferon- $\beta$ Induces Brain-Derived Neurotrophic Factor in Peripheral Blood Mononuclear Cells of Multiple Sclerosis Patients," Journal of Neuroimmunology, Vol. 197, No. 2, 2008, pp. 147-151. doi:10.1016/j.jneuroim.2008.04.033

[37] C. Hahn, A. P. Islamian, H. Renz and W. A. Nockher, "Airway Epithelial Cells Produce Neurotrophins and Promote the Survival of Eosinophils during Allergic Airway Inflammation," Journal of Allergy and Clinical Immunology, Vol. 117, No. 4, 2006, pp. 787-794. doi:10.1016/j.jaci.2005.12.1339

[38] O. Noga, et al., "The Production, Storage and Release of the Neurotrophins Nerve Growth Factor, Brain-Derived Neurotrophic Factor and Neurotrophin-3 by Human Peripheral Eosinophils in Allergics and Non-Allergics," Clinical \& Experimental Allergy, Vol. 33, No. 5, 2003, pp. 649-654. doi:10.1046/i.1365-2222.2003.01586.x

[39] O. Noga, et al., "Regulation of NGF and BDNF by Dexamethasone and Theophylline in Human Peripheral Eosinophils in Allergics and Non-Allergics," Regulatory Peptides, Vol. 132, No. 1, 2005, pp. 74-79. doi:10.1016/j.regpep.2005.09.023

[40] B. Rost, et al., "Monocytes of Allergics and Non-Allergics Produce, Store and Release the Neurotrophins NGF, BDNF and NT-3," Regulatory Peptides, Vol. 124, No. 1, 2005, pp. 19-25. doi:10.1016/j.regpep.2004.06.024

[41] R. M. Johnstone, "Exosomes Biological Significance: A Concise Review," Blood Cells, Molecules, and Diseases, Vol. 36, No. 2, 2006, pp. 315-321. doi:10.1016/i.bcmd.2005.12.001

[42] M. P. Hunter, et al., "Detection of microRNA Expression in Human Peripheral Blood Microvesicles," PloS ONE, Vol. 3, No. 11, 2008, Article ID: e3694. doi:10.1371/journal.pone.0003694

[43] M. Simons and G. Raposo, "Exosomes: Vesicular Carriers for Intercellular Communication," Current Opinion in Cell Biology, Vol. 21, No. 4, 2009, pp. 575-581. doi:10.1016/j.ceb.2009.03.007

[44] Y. Lee, S. E. Andaloussi and M. J. Wood, "Exosomes and Microvesicles: Extracellular Vesicles for Genetic Information Transfer and Gene Therapy," Human Molecular Genetics, Vol. 21, No. R1, 2012, pp. R125-R134. doi: $10.1093 / \mathrm{hmg} / \mathrm{dds} 317$

[45] A. Lakkaraju and E. Rodriguez-Boulan, "Itinerant Exosomes: Emerging Roles in Cell and Tissue Polarity," 
Trends in Cell Biology, Vol. 18, No. 5, 2008, pp. 199-209. doi:10.1016/j.tcb.2008.03.002

[46] K. K. Jain, "Nanobiotechnology-Based Strategies for Crossing the Blood-Brain Barrier," Nanomedicine, Vol. 7, No. 8, 2012, pp. 1225-1233. doi:10.2217/nnm.12.86

[47] M. J. Wood, A. J. O'Loughlin and S. Lakhal, "Exosomes and the Blood-Brain Barrier: Implications for Neurological Diseases," Therapeutic Delivery, Vol. 2, No. 9, 2011, pp. 1095-1099.

[48] X. Zhuang, et al., "Exosomes Are Endogenous Nanoparticles That Can Deliver Biological Information between Cells," Advanced Drug Delivery Reviews, Vol. 65, No. 3, 2012, pp. 342-347. doi:10.1016/j.addr.2012.07.002

[49] S. M. van Dommelen, et al., "Microvesicles and Exosomes: Opportunities for Cell-Derived Membrane Vesicles in Drug Delivery," Journal of Controlled Release, Vol. 161, No. 2, 2012, pp. 635-644. doi:10.1016/i.jconrel.2011.11.021

[50] I. B. Borecki, et al., "Evidence for Multiple Determinants of the Body Mass Index: The National Heart, Lung, and Blood Institute Family Heart Study," Obesity Research, Vol. 6, No. 2, 1998, pp. 107-114. doi:10.1002/j.1550-8528.1998.tb00323.x

[51] W. Duan, Z. Guo and M. P. Mattson, "Brain-Derived Neurotrophic Factor Mediates an Excitoprotective Effect of Dietary Restriction in Mice," Journal of Neurochemistry, Vol. 76, No. 2, 2001, pp. 619-626. doi:10.1046/j.1471-4159.2001.00071.x

[52] N. Maswood, et al., "Caloric Restriction Increases Neurotrophic Factor Levels and Attenuates Neurochemical and Behavioral Deficits in a Primate Model of Parkinson's Disease," Proceedings of the National Academy of Sciences of the United States of America, Vol. 101, No. 52, 2004, pp. 18171-18176. doi:10.1073/pnas.0405831102

[53] J. B. Johnson, et al., "Alternate Day Calorie Restriction Improves Clinical Findings and Reduces Markers of Oxidative Stress and Inflammation in Overweight Adults with Moderate Asthma," Free Radical Biology \& Medicine, Vol. 42, No. 5, 2007, pp. 665-674. doi:10.1016/j.freeradbiomed.2006.12.005

[54] L. R. Guimaraes, et al., "Serum Levels of Brain-Derived Neurotrophic Factor in Schizophrenia on a Hypocaloric Diet," Progress in Neuro-Psychopharmacology \& Biological Psychiatry, Vol. 32, No. 6, 2008, pp. 1595-1598. doi:10.1016/j.pnpbp.2008.06.004

[55] G. Muller, "Novel Target Identification Technologies for the Personalised Therapy of Type II Diabetes and Obesity," Immunology, Endocrine \& Metabolic Agents-Medicinal Chemistry, Vol. 12, No. 3, 2012, pp. 183-207.

[56] S. Lakhal and M. J. Wood, "Exosome Nanotechnology: An Emerging Paradigm Shift in Drug Delivery," BioEssays: News and Reviews in Molecular, Cellular and Developmental Biology, Vol. 33, No. 10, 2011, pp. 737-741. doi:10.1002/bies.201100076

[57] S. Lakhal, S. El Andaloussi, A. J. O’Loughlin, J. H. Li and M. M. Wood, "RNAi Therapeutic Delivery by Exosomes," Springer, Berlin, 2013. doi:10.1007/978-1-4614-4744-3 9 